\title{
Past, present, and future of hepatitis $b$ and fatty liver in Bangladesh
}

\begin{abstract}
Chronic hepatitis B (HBV) is one of the major diseases of mankind, estimated to cause about 686,000 deaths per year mostly from liver cancer and cirrhosis. And globally about 240 million people are chronically infected with hepatitis B. Nonalcoholic fatty liver disease (NAFLD) is an emerging commonest cause of chronic liver disease in the world. We have searched for CHB, NAFLD in PUBMED, Google scholar and hard copies of local journals and related available articles were included in this review. Along with 184 countries of the world Bangladesh adopted hepatitis B vaccine in his EPI (expanded program on immunization) schedule for its prevention. And now about $95 \%$ of children are under cover of Hep B vaccine. Along with globally in last two decades' seroprevalence of HBsAg reduced about four times in Bangladesh. The prevalence of recorded nonalcoholic fatty liver disease (NAFLD) varies considerably by ethnic group and Bangladeshi ethnicity is an independent risk factor for NAFLD. The prevalence of NAFLD in Bangladesh is vary from $4 \%-18.4 \%$ and it is increasing day by day. About $40 \%$ of them are nonalcoholic steatohepatitis (NASH). They are in danger of progression to cirrhosis and hepatocellular carcinoma (15-19\%) in next 5 to 10 years. Now it's becoming a silent killer for our nation. Gradual development of affluence, sedentary life style and increasing prevalence of diabetes contributed behind it. No effective treatment is available till now. Life style change by diet, exercise and weight reduction is the main stay of treatment. NAFLD involve multiple organs that leads to death due to cardiac, neurological and liver disease. Government and health department should take multidisciplinary action programs in awareness building and make a national guideline for fatty liver management.
\end{abstract}

Keywords: hepatitis B, fatty liver, non-alcoholic fatty liver disease, NAFLD, Bangladesh
Volume 6 Issue 3 - 2017

\section{Shahinul Alam,' Golam Azam, ${ }^{2}$ Golam \\ Mustafa, ${ }^{3}$ Mahabubul Alam, ${ }^{3}$ Nooruddin Ahmad $^{3}$}

'Department of Hepatology, Bangabandhu Sheikh Mujib Medical University, Bangladesh

${ }^{2}$ Gastrointestinal, Hepatobiliary and Pancreatic Disorders (BIRDEM), Bangladesh

${ }^{3}$ Department of Hepatology, Bangabandhu Sheikh Mujib Medical University, Bangladesh

\section{Correspondence: Shahinul Alam, Associate professor, Department of Hepatology, Bangabandhu Sheikh Mujib Medical University, Shahbag, Dhaka- 1000, Bangladesh, Tel 8.801973007173, Email shahinul67@yahoo.com}

Received: October 01, 2016 | Published: March 7, 2017

\section{Introduction}

Hepatitis B virus (HBV) infection is a threat for people of all age groups of Bangladesh and other South Asian countries. ${ }^{1}$ Globally, in 2013, approximately $686,000 \mathrm{HBV}$-infected persons died from causes related to acute infection (69,000 deaths), cirrhosis (317,000 deaths) and HBV-associated liver cancer (300,000 deaths);Hepatocellular carcinoma the sixth most common cancer globally and the second leading cause of cancer-related death worldwide. ${ }^{2}$ Along with 184 countries of the world Bangladesh adopted hepatitis B vaccine in his EPI (expanded program on immunization) schedule. ${ }^{2}$ Prevalence of HBV among children and adult both has been decreased than previous time. Nonalcoholic fatty liver disease (NAFLD) has become the most common cause of liver disease with prevalence of $20-33 \% .^{3}$ In the Asia-Pacific region the prevalence of NAFLD has increased remarkably over the years affecting up to $30 \%$ of the general population. ${ }^{4}$ Bangladeshi ethnicity is an important independent risk factor for NAFLD. ${ }^{5}$ For further planning it is the immediate need to assess the future direction for two major liver diseases on the basis of past and present status in Bangladesh. The aim of this review is to grade the danger of chronic hepatitis B (CHB) and NAFLD from existing knowledge and to aware the health care provider, planner and administrator of Bangladesh.

\section{Materials and methods}

We searched the PUBMED, Google Scholar and Bangla JOL for key words of CHB, NAFLD, Fatty liver, Bangladesh. Relevant full article, abstract, review, mini review, editorial and conference proceeding are included in this review.

\section{Global epidemiology of hepatitis B \& fatty liver}

Universally an estimated 240 million people are chronically infected with hepatitis B. ${ }^{6}$ Hepatitis B can causes both acute and chronic liver disease and is a major cause of mortality and morbidity. ${ }^{7}$ It is one of the major diseases of mankind, estimated to cause about 800,000 deaths per year mostly from liver cancer and cirrhosis. ${ }^{8}$ This represents a decrease of $31 \%$ in hepatitis B surface antigen (HBsAg) prevalence as compared to the former published figures of 350-400 million. ${ }^{8}$ The history of the epidemiology of hepatitis B represents a landmark in the general understanding of viral infections, their distributions and their outcomes. In 2010 and 2014 resolutions of the World Health Assembly, have acknowledged at the political level that viral hepatitis is a global public health problem, ranking $\mathrm{HBV}$ as the 15th cause of death in all cause of global mortality. ${ }^{8}$ The global prevalence of chronic carriage varies between 0.1 and more than $20 \%{ }^{6}$ Approximately $15-40 \%$ of chronically infected patients will develop liver cirrhosis, liver failure, or hepatocellular carcinoma and $15-25 \%$ will ultimately die. ${ }^{6,8}$ However, It can be prevented by currently available safe and effective vaccine. ${ }^{6}$ It is important to note the great impact of routine infant and childhood hepatitis B immunization programs, which have caused a dramatic reduction of HBsAg carriage in immunized cohorts of children, and have led to significant decreases in HBV transmission and the occurrence of related cirrhosis and liver cancer in various populations. ${ }^{8}$

For last one decade trend of number of chronically HBV infected people is decreasing (Figure 1). In around 2005 globally about 350 million people were chronically infected with HBV, where in 2016 about 240 million are now chronically infected with HBV. ${ }^{9}$ Globally 
number of people death due to HBV complication has been reduced about $31.4 \%$ in last few years (Figure 2). In 2008 globally number of death due to HBV complication was about one million, but now it's about 0.686 million. ${ }^{9,10}$

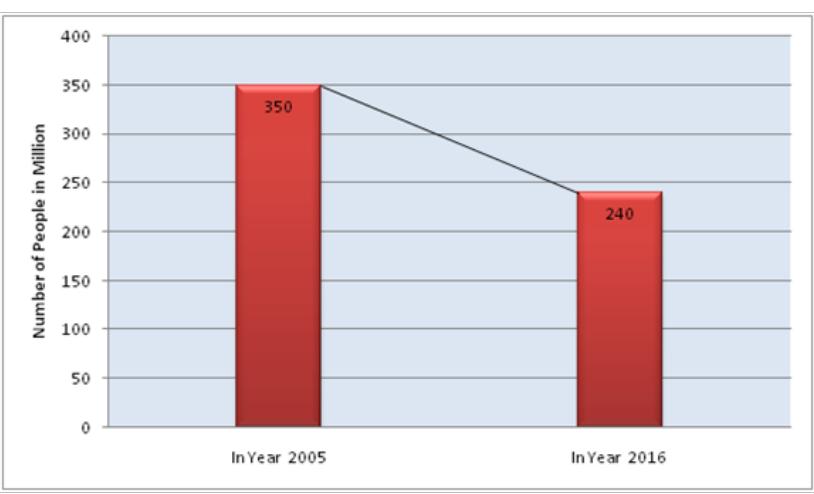

Figure I Globall Number of People Chronically Infected with HBV.

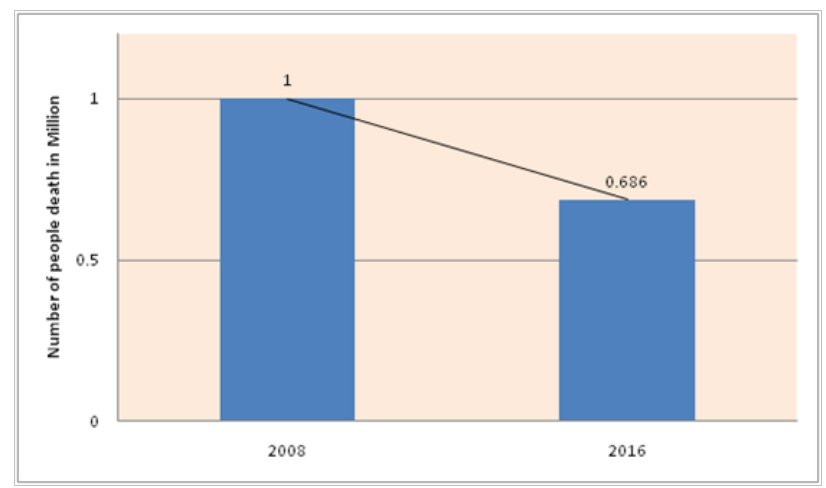

Figure 2 Year vs Year global number of people death due to HBV complication.

Global prevalence of NAFLD is $25.24 \%{ }^{11}$ However, the condition is observed in up to $75 \%$ of obese people, ${ }^{12}$ despite no evidence of excessive alcohol consumption. NAFLD is the most common cause of abnormal liver function tests in the United States. ${ }^{13}$ Fatty livers occur in $33 \%$ of European-Americans, $45 \%$ of Hispanic-Americans, and $24 \%$ of African-Americans. ${ }^{14}$

Nonalcoholic fatty liver disease (NAFLD) has become the most common cause of liver disease and abnormal liver function test in industrialized countries ${ }^{15}$ with prevalence of $20-33 \% .^{3}$ There is lower prevalence and lower degree of liver cell injury in African American population while higher prevalence is reported in Asians and Hispanics with advanced grade of liver damage compared to other ethnicities. ${ }^{16}$ NAFLD should be considered not only a liver specific disease but also an early mediator of systemic diseases. Therefore, NAFLD is usually associated with cardiovascular disease, type 2 diabetes, obesity, and dyslipidemia. ${ }^{17}$ NAFLD is highly prevalent in the general population and is associated with increased cardiovascular morbidity and mortality. ${ }^{17}$ The prevalence of NAFLD in South Asia and South East Asia ranges from 5\%-30\%. ${ }^{18}$ In India it varies from $5-28 \%$ in general population especially those who are undergoing healthy checkups. ${ }^{19}$

\section{Prevalence of hepatitis B \& fatty liver among Bangladesh population}

Like a threat for world, Hepatitis B infection is a threat for people of all age groups of Bangladesh and other South Asian countries. ${ }^{1}$ Bangladesh with a population of 150 million had a
HBsAgseroprevalence of $7.5 \%$ in healthy adult population. ${ }^{20}$ In Bangladesh, most HBV infections occur in childhood as suggested by the high rate of interfamilial HBV infection, history of low rate of acute hepatitis and large number of younger populations affected. ${ }^{21}$ In the past HBV prevalence was estimated to be $2.3 \%-9.7 \%$ with an approximate carrier pool of about 10 million. Bangladesh is in intermediate endemic zone for HBV and younger populations are mostly affected. ${ }^{22}$ Genotypically, it was found that for Bangladesh the prevalent genotype was genotype $\mathrm{C}$ (sub genotype $\mathrm{C}$ ) which accounted for $48.7 \%$ and other genotypes found were genotype A $(23.1 \%)$ and genotype D $(28.2 \%)(23)$. Predominant subtypes in Bangladesh were adr (41\%) followed by subtype adw2 (28.2\%), ayw3 (25.6\%), and others. ${ }^{23}$

The prevalence of recorded NAFLD varies considerably by ethnic group and Bangladeshi ethnicity is an independent risk factor for NAFLD. In a study in the UK, liver function tests were performed on 218,032 patients, of whom 31,627 had elevated serum transaminases. ${ }^{5}$ The prevalence of NAFLD was the most frequently recorded liver disease and was most common among Bangladeshi patients. ${ }^{5}$ Prevalence of NAFLD in general population of Bangladesh has been estimated to vary from 4 to $18.4 \%$, which jumps up to $49.8 \%$ in diabetic patients..$^{24,25}$

From our observation we have been found that, like other noncommunicable disease, prevalence of NAFLD has been increasing for last several years. In 2000, more than 50\% Bangladeshi people were died due to communicable disease ${ }^{26}$ and $27 \%$ of people were died due to non-communicable disease ${ }^{26}$ (Figure 4). But in 2012 the rate of death due to non-communicable disease has been increased in $43 \%(26)$ (Figure 3). It means prevalence of non-communicable diseases (like NAFLD, Diabetics, dyslipidemia etc) is increasing in Bangladesh.

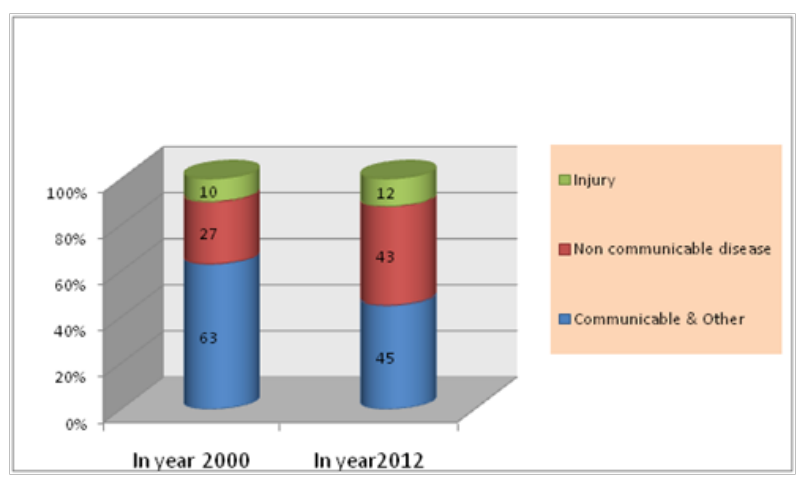

Figure 3 Distribution of Years of Life Lost by Major Causes Group in Bangladesh.

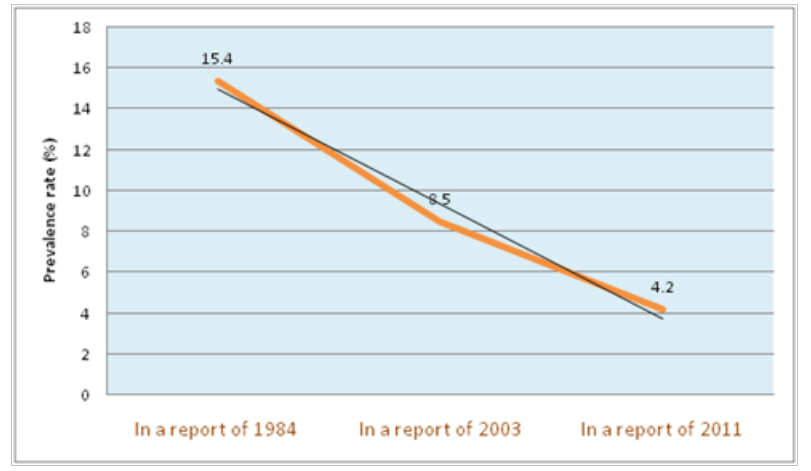

Figure 4 Trend of Seroprevalance of HBsAg among Bangladeshi children. 


\section{Last two decades' trend of prevalence of hepatitis of $B$ in Bangladesh}

All the manuscripts were collected from PubMed and were published in PubMed within January 1980 to December 2015 (search key words was "Hepatitis B Epidemiology" AND "Bangladesh"). Overall prevalence of carrier rates of $\mathrm{HBV}$ infection varies from 3 to $10 \%$ in recent years. ${ }^{27,28}$

Trend of sprevalence of HBsAg in both children and adult Bangladeshi population is negative. In last two decades seroprevalence among child has been reduced about more than three times (Figure 4). In 1984 Islam NM et al reported that, prevalence of HBsAg among children was $15.4 \% ;{ }^{29}$ in 2003 Zakir H et al. ${ }^{30}$ reported $8.5 \%$. In 2011 Alam S et al. ${ }^{22}$ showed in his study that, it was $4.2 \%$ and was declining from previous studies. ${ }^{22}$

In case of adult, last two decades's eroprevalence of HBsAg reduced about four times (Figure 5). In 1984 Islam NM et al. ${ }^{29}$ reported 27.2\%; in 1991 Ahmad Q et al. ${ }^{31}$ reported 8.6\%; 1997 Rahman M et al. ${ }^{32}$ reported 6.4\%; in 2008 Mahtab MA et al. ${ }^{33}$ reported $5.5 \%$ and in 2011 Rudro S et al. ${ }^{34} 6.5 \%$. Overall prevalence of HBV in Bangladeshi general population has been decreasing (Figure 6) for last several years. In 2007 Rahman MT et al. ${ }^{35}$ reported 8.1\%; in 2015 Rukunuzzaman $\mathrm{M}$ et al. ${ }^{27}$ reported 3\%.

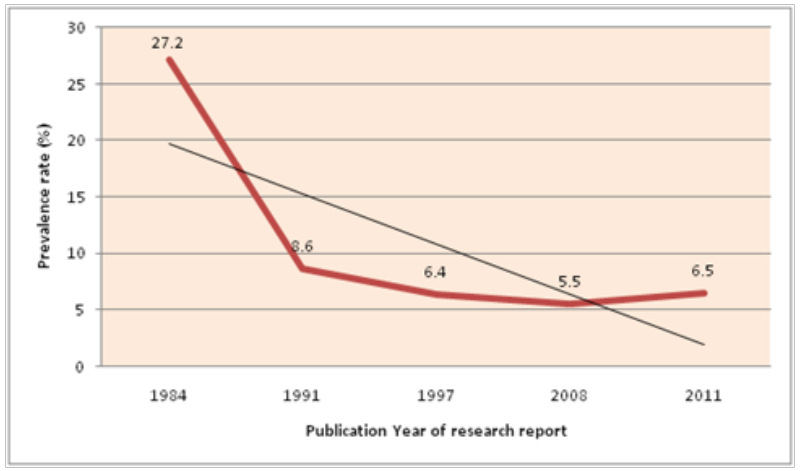

Figure 5 Trend of Seroprevalance of HBsAg among Bangladeshi Adult.

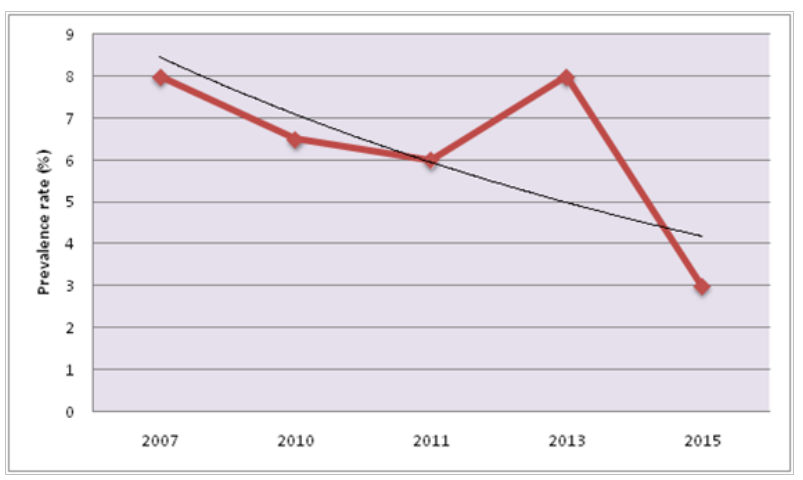

Figure 6 Overall prevalence of HBV in Bangladeshi general population.

\section{Overview on EPI and HBV vaccination in Bangladesh}

EPI or expanded program on immunization is the vaccination campaign or schedule in Bangladesh. It started in 1979 as a pilot project to eradicate or eliminate some vaccine preventable diseases. ${ }^{36}$ HBV vaccine has been incorporated in EPI schedule since 2004 in Bangladesh and immunoprophylaxis of babies of HBsAg positive mother and post exposure prophylaxis are effective ways of prevention. ${ }^{37}$ As many as $90 \%$ of infants born to Hepatitis B e Antigen ( $\mathrm{HBeAg}$ ) positive mothers become carriers themselves and, therefore, in long term are more likely to develop chronic liver disease. ${ }^{38}$

According to global health observatory data repository report ${ }^{26}$ Bangladesh is doing very well in EPI vaccination. About $95 \%$ of Bangladeshi children are now vaccinated with Hepatitis B vaccine (Figure 7). In 2003 only 5\% under one year infant were under coverage of this vaccine. After incorporation in EPI the number has been gradually increasing. And since 2007 less than one year age infant hepatitis B vaccination coverage rate is $95 \%$, where globally it is $82 \%$ in 2014 .

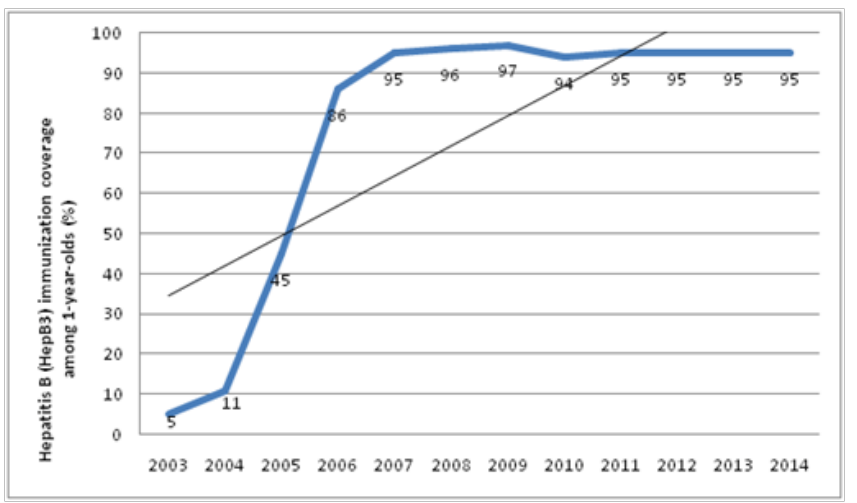

Figure 7 Hepatitis B immunization coverage in Bangladesh 2003-20I4.

\section{Current research Work's findings on NAFLD in Bangladesh- NAFLD becoming an emerging threat for us}

Non-alcoholic fatty liver disease (NAFLD) is an emerging problem in Hepatology ${ }^{39}$ and is a major cause of liver-related morbidity ${ }^{40}$ Females are the predominant sufferers of NAFLD in Bangladesh. ${ }^{41}$ It is a metabolic disease commonly associated with obesity, type 2 diabetes, and all features of insulin resistant syndrome. Subclinical chronic inflammation and insulin resistance seem to be independent mediators of the association between NAFLD and prediabetes..$^{42}$ Although insulin resistance (IR) is strongly associated with nonalcoholic fatty liver disease (NAFLD), but it is not the sole predictor of the pathogenesis of NAFLD. ${ }^{43}$

The Asia Pacific region is ethnically most diverse and most densely populated region compare to other continents in the world. Recent socioeconomic changes with increased affluence and changes in lifestyle have resulted in an emerging epidemic of non-communicable diseases such as T2DM and NAFLD. Along with neighbor country prevalence of NAFLD is increasing ${ }^{39}$ in Bangladesh. And it's becoming a silent killer for our nation.

Adipose tissue-derived hormone leptin plays a functional role in glucose tolerance. ${ }^{44}$ It does not mean that only obese people are at risk of NAFLD, study showed that, among NAFLD patients of Bangladesh $25.6 \%$ was non-obese, and $53.1 \%$ of non-obese NAFLD cases had nonalcoholic steatohepatitis (NASH) ${ }^{45}$ Though they were not obese by BMI grade, they were metabolically similar to obese. Males were predominant in the non-obese, whereas females in the obese. NASH and fibrosis were similar in the obese and non-obese. ${ }^{45}$ The prevalence of NASH is high. Diabetes/metabolic syndromeare the main culprit in developing NASH. Study recommends ALT \&GGT are the biochemical markers of NASH and liver biopsy is the gold standard to detect NASH. Biopsy is recommended in NAFLD 
patients who have diabetes/metabolic syndrome and elevated ALT, serum gamma-glutamyl transpeptidase (GGT) ${ }^{41} \mathrm{NASH}$ of $40 \%$ in NAFLD patients of Bangladesh are in great danger to progress to cirrhosis and hepatocellular carcinoma in next 5 to 10 years. ${ }^{45}$ These high number of NASH warrants attention of health policy makers to address the magnitude of the problem.

Treatment is mostly control of underlying disorders and dietary advice, exercise, insulin sensitizers, antioxidants, or cytoprotective agents. ${ }^{39,42,43}$ Telmisartan and life style modification could improve steatosis, ballooning, lobular inflammation, and fibrosis. Telmisartan improved NAS and fibrosis score in NASH with insignificant adverse events. ${ }^{46}$

\section{Natural history of HBV infection}

Perinatal infection from infected mothers to their infants or horizontal infection early in childhood from exposure to HBsAg positive family members are the main routes of $\mathrm{HBV}$ transmission in high endemic area, such as South-East Asia, most Africa, Pacific Islands and the Arctic, whereas in low endemic regions, such as Western countries, hepatitis B is primarily a disease of adolescents and adults as a result of high risk sexual activity and injection drug use. ${ }^{47} \mathrm{HBV}$ infection is a dynamic process characterized by replicative and non-replicative phases based on virus host interaction, which are present in some form in all infected patients (Figure 8) ${ }^{47}$

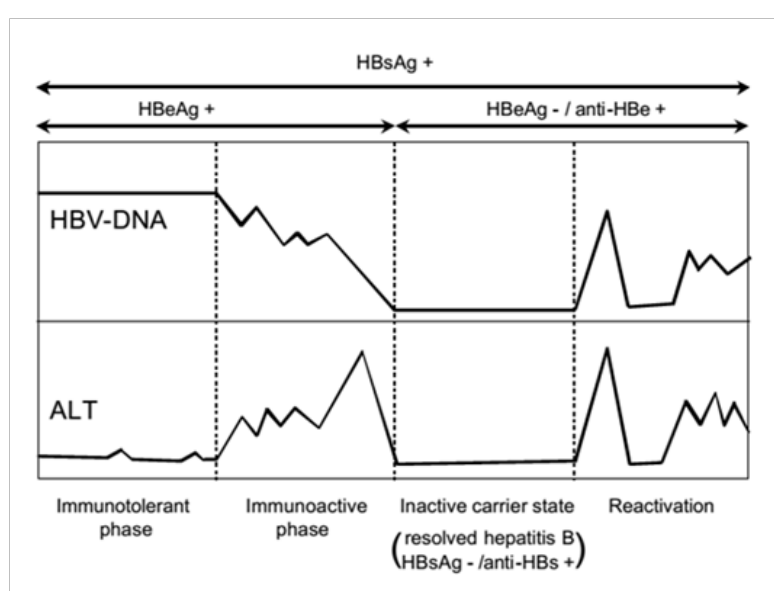

Figure 8 Natural course of hepatitis B virus (HBV) infection.

The presence of circulating HBsAg, hepatitis $\mathrm{B}$ e antigen (HBeAg) and high levels of serum HBV-DNA identifies the first immunotolerant phase. The perinatal infection this phase often lasts for decades. During this phase patients have no symptoms, normal or slightly increased serum alanine aminotransferase (ALT) levels and minimal histological activities, which implies that there is a lack or very weak immune response against the infected hepatocytes. ${ }^{47}$ The natural history of HBV infection of Bangladesh is similar because most of the HBV infection is acquired in Bangladesh at perinatal life. The incidence of cirrhosis appears to be about 2-fold higher in $\mathrm{HBeAg}$ negative compared to $\mathrm{HBeAg}$ positive chronic hepatitis. ${ }^{48}$ In the cirrhotic patient the 5 -year cumulative risk of developing hepatocellular carcinoma is $17 \%{ }^{49}$

The spectrum of disease and natural history of chronic HBV infection are diverse and variable, ranging from immune tolerance to inactive carrier state, passing through a more or less progressive chronic hepatitis, potentially evolving to cirrhosis and hepatocellular carcinoma (HCC). ${ }^{49}$

\section{Natural history of NAFLD}

A patient with liver steatosis we are facing two different possibilities: the first a patient with only fatty liver accumulation which is considered as non NASH fatty liver (NNFL)and the second a patient with fatt accumulation, necroinflammation (NASH) and fibrosis. ${ }^{50}$ These two clinical conditions don't share the same natural history but, even if the simple NNFL without necroinflammation and fibrosis is rightly considered a "non-progressive" disease, and conversely NASH a "progressive" one, it has to be pointed out that the most important risk of death of both is not represented by liver related death. ${ }^{50}$ Patients with NAFLD are at risk of death for cardiovascular disease and cancer more than for liver disease..$^{51} \mathrm{NASH}$ may progress to significant fibrosis of $35 \%$ and even cirrhosis of $15 \%$ in 5 years. Progression to fibrosis ranges from 15 to $40 \%$ in NASH and cirrhosis 15 to $19 \%$ in 9 years. ${ }^{52}$

Hepatocellular Carcinoma: NAFLD is an independent risk factor of $\mathrm{HCC}$, in the majority of cases in the presence of cirrhosis, even if it has been reported also in non-cirrhotic patients..$^{52}$ In patients with NASH-related cirrhosis the cumulative incidence of HCC ranges from $2.4 \%$ to $12.8 \%,{ }^{52}$ but, even if it is lower than that in HCV cirrhotic patients, the absolute burden of NASH-related HCC is higher due to the higher number of patients with NAFLD in respect to HCV infected ones. It is very likely that this trend will continue to increase in the future, when the new therapies for hepatitis $\mathrm{C}$ and $\mathrm{B}$ and prevention programs will further reduce the size of viral infections of the liver. ${ }^{50,53}$

\section{Management of hepatitis B \& NAFLD}

A brief on "Asian-Pacific clinical practice guidelines on the management of hepatitis B: a 2015 update" ${ }^{54}$ has been recommended several drugs for the management of CHB eg: Nucleoside and nucleotide analogue eg: tenofovir, entecavir. Immunomodulatory drug eg: pegylated interferon is also recommended. All the drugs are available in Bangladesh produced by local pharmaceutical companies and patients are getting it with lowest price in the world. Hossain et al. ${ }^{44}$ suggests a comprehensive updated guideline of Pharmaceutical and non-pharmaceutical treatment for NAFLD, which has been published in 2016. A brief on this guideline has been shown in Table 1.

\section{Conclusion}

HBV still it is a major cause of chronic liver disease in Bangladesh. But with the increase of awareness and nationwide large scale vaccination program, the prevalence of $\mathrm{HBV}$ has been decreasing in Bangladesh. And we believe we will achieve the WHO goal target of vision 2030 with elimination of hepatitis B. It's really good news for Bangladesh that for last few years some native pharmaceuticals companies are producing anti-viral drugs. So treatment cost is become more affordable than before. With the changes in socioeconomic condition and life style modernization, the prevalence rate of noncommunicable disease is increasing. Leading cause of chronic liver disease is drifting from infectious to noninfectious diseases and the contribution of NAFLD is progressively increasing.

From the evidences it is clear that NAFLD will be leading cause of chronic liver disease in the future. It is the time demand to aware the stalk holders to confront this public health issue. In comparison with Hepatitis B, prevention of fatty liver is very poor. So government and health department should take multidisciplinary action programs in awareness building and make a national guideline for fatty liver management. 
Table I Summary of treatment options for NAFL/NASH. ${ }^{3}$

\begin{tabular}{|c|c|c|}
\hline Treatment strategy & Medication/Intervention & Comment \\
\hline \multirow{4}{*}{ Lifestyle modification } & Weight loss & $\begin{array}{l}5-10 \% \text { weight loss can lead to biochemical and histological } \\
\text { improvement }\end{array}$ \\
\hline & Hypocaloric diet alone & $\begin{array}{l}\text { Better response when combined with exercise and reduced } \\
\text { carbohydrate and fat }\end{array}$ \\
\hline & Dietary composition & $\begin{array}{l}\text { Diet should include addition of PUFA and decreased } \\
\text { saturated and transfatty acids. Mediterranean diet has } \\
\text { shown improvement in ALT, insulin levels, and histological } \\
\text { markers. }\end{array}$ \\
\hline & Exercise alone & Effective even without weight loss \\
\hline \multirow{5}{*}{ Insulin sensitivity } & Diet plus exercise & Greatest beneficial effect \\
\hline & Bariatric surgery & Could be beneficial in reversing NASH. \\
\hline & Thiazolidinediones & $\begin{array}{l}\text { For patients with NASH, they improve insulin resistance, } \\
\text { biomarkers, steatosis, and inflammation. caution should be } \\
\text { taken in regard to cardiovascular risks. }\end{array}$ \\
\hline & Metformin & It offers no additional biochemical or histological benefits \\
\hline & Meglitinides and incretinmimetics & GLP-I analog has shown histological improvement \\
\hline \multicolumn{3}{|l|}{ Antioxidant } \\
\hline & Vitamin E & $\begin{array}{l}\text { Improves histological markers in non-diabetic NASH. may } \\
\text { have greater benefit when combined with other agents }\end{array}$ \\
\hline Anti-inflammatory & Pentoxifylline & May improve liver enzymes and histology \\
\hline Probiotics & & $\begin{array}{l}\text { May improve liver enzymes, insulin resistance, and anti- } \\
\text { inflammatory markers }\end{array}$ \\
\hline \multirow[t]{2}{*}{$\begin{array}{l}\text { Cytoprotective and antiapoptotic } \\
\text { agents }\end{array}$} & Ursodeoxycholic acid & $\begin{array}{l}\text { May improve liver enzymes and histology, but further well- } \\
\text { designed studies are needed }\end{array}$ \\
\hline & RAAS & $\begin{array}{l}\text { Small studies show improvement in liver enzymes and } \\
\text { histology, but larger randomized controlled studies are } \\
\text { warranted }\end{array}$ \\
\hline Herbal & Milk thistle & $\begin{array}{l}\text { May improve liver chemistry and histology especially in } \\
\text { combination with other agents such as vitamin E and } \\
\text { phospholipids }\end{array}$ \\
\hline
\end{tabular}

\section{Acknowledgments}

None.

\section{Conflicts of interest}

The authors declare there is no conflict of interests.

\section{Funding}

None.

\section{References}

1. Biswas T, Biswas SK. Seroprevalence of hepatitis b infection among first-time blood donors in Faridpur, Bangladesh. International Journal of Medical Students. 2016;4(1).

2. Kane MA, Roudot Thoraval F, et al. Global progress in the control of viral hepatitis and acceptable delay in Hepatitis B immunization. Human vaccines \& immunotherapeutics. 2016:1-4.

3. Hossain N, Kanwar P, Mohanty SR. Comprehensive Updated Review of Pharmaceutical and Nonpharmaceutical Treatment for NAFLD. Gastroenterol Res Pract. 2016:7109270.
4. Chan WK, Tan AT, Vethakkan SR, et al. Low physical activity and energy dense Malaysian foods are associated with non-alcoholic fatty liver disease in centrally obese but not in non-centrally obese patients with diabetes mellitus. Asia Pac J Clin Nutr. 2015;24(2):289-298.

5. Alazawi W, Mathur R, Abeysekera K, et al. Ethnicity and the diagnosis gap in liver disease: a population-based study. Br J Gen Pract. 2014;64(628):e694-702.

6. WHO. Hepatitis B. 2015.

7. Alavian SM, Fallahian F, Lankarani KB. The changing epidemiology of viral hepatitis B in Iran. J Gastrointestin Liver Dis. 2007;16(4):403-406.

8. Lavanchy D, Kane M. Global Epidemiology of Hepatitis B Virus Infection. Hepatitis B Virus in Human Diseases. 2016:187-203.

9. WHO. Hepatitis B fact sheet 2016. 2016.

10. CDC. Viral hepatitis-statistics \& surveillance. 2014.

11. Younossi ZM, Koenig AB, Abdelatif D, et al. Global epidemiology of nonalcoholic fatty liver disease-Meta-analytic assessment of prevalence, incidence, and outcomes. Hepatology. 2016;64(1):73-84.

12. Hamaguchi M, Kojima T, Takeda N, et al. The metabolic syndrome as a predictor of nonalcoholic fatty liver disease. Ann Intern Med. 2005; 143(10):722-728. 
13. Angulo P. Nonalcoholic fatty liver disease. $N$ Engl $J$ Med. 2002;346(16):1221-1231.

14. DeNoon DJ. Fatty liver disease: genes affect risk. 2008.

15. Argo CK, Caldwell SH. Epidemiology and natural history of nonalcoholic steatohepatitis. Clin Liver Dis. 2009;13(4):511-531.

16. Mohanty SR, Troy TN, Huo D, et al. Influence of ethnicity on histological differences in non-alcoholic fatty liver disease. $J$ Hepatol. 2009;50(4):797-804.

17. Fotbolcu H, Zorlu E. Nonalcoholic fatty liver disease as a multi-systemic disease. World J Gastroenterol. 2016;22(16):4079.

18. Parkash O, Hamid S. Are we ready for a new epidemic of under recognized liver disease in South Asia especially in Pakistan? Non alcoholic fatty liver disease. J Pak Med Assoc. 2013;63(1):95-99.

19. Amarapurkar D, Kamani P, Patel N, et al. Prevalence of non-alcoholic fatty liver disease: population based study. Ann Hepatol. 2007;6(3):161163.

20. Shahinul Alam NA, Khorshed Alam, Golam Mustafa, et al. Correlation between hepatitis B viral DNA load and extent of liver pathology in patients with chronic hepatitis B. Hepatitis Monthly. 2008;8(3):185-189.

21. Ahmad N, Alam S, Mustafa G, et al. e-antigen-negative chronic hepatitis B in Bangladesh. Hepatobiliary Pancreat Dis Int. 2008;7(4):379-382.

22. Ahmad N AS, Mustafa G, Chowdhury ZR, et al. Seroprevalence of hepatitis $\mathrm{B}$ virus in parents and under 5 years children in a rural area of Bangladesh. BSMMU J. 2011;4(1):8-11.

23. Rahman MA, Hakim F, Ahmed M, et al. Prevalence of genotypes and subtypes of hepatitis B viruses in Bangladeshi population. Springer Plus. 2016;5:278.

24. MI H NAFLD in Bangladesh. Abstract Book 1st Conference of SASL; 2013. 69 p.

25. Rahman MM KM, Begum H, Haque M, et al. Prevalence and risk factors of nonalcoholic fatty liver disease in a rural community of South Asia. Gastroenterology research and practice. 2015;148:S1045-1046.

26. WHO. Global Health Observatory data repository. 2014.

27. Rukunuzzaman M, Karim MB. Chronic Hepatitis B in Children - A Review. Mymensingh Med J. 2015;24(3):649-656.

28. Ishaque SM, Mahmuduzzaman M, Rahman MA, et al. Clinical, biochemical, virological and sonographic profile of incidentally detected asymptomatic HBsAg positive subjects, in Bangladesh. Mymensingh Med J. 2014;23(1):81-85.

29. Islam $\mathrm{MN}$, Islam KM, Islam N. Hepatitis-B virus infection in Dhaka, Bangladesh. Bangladesh Med Res Counc Bull. 1984;10(1):1-6.

30. Zaki H, Darmstadt GL, Baten A, et al. Seroepidemiology of hepatitis B and delta virus infections in Bangladesh. J Trop Pediatr. 2003;49(6):371374 .

31. Ahmad Q, Chowdhury SG, Islam MN, et al. HBsAg amongst unscreened operated patients. Bangladesh Med Res Counc Bull. 1991;17(1):11-16.

32. Rahman M, Amanullah, Sattar H, et al. Sero-epidemiological study of hepatitis B virus infection in a village. Bangladesh Medical Research Council bulletin. 1997;23(2):38-41.

33. Mahtab MA, Rahman S, Karim MF, et al. Epidemiology of hepatitis $\mathrm{B}$ virus in Bangladeshi general population. Hepatobiliary Pancreat Dis Int. 2008;7(6):595-600.

34. Rudra S, Chakrabarty P, Poddar B. Prevalence of hepatitis B and hepatitis $\mathrm{C}$ virus infection in human of Mymensingh, Bangladesh. Mymensingh Med J. 2011;20(2):183-186.
35. Rahman MT, Sultana R, Chowdhury SR. Seropositivity and pattern of viral hepatitis in clinically suspected cases of hepatitis in Dhaka city. Bangladesh Med Res Counc Bull. 2007;33(3):103-106.

36. Ahmed DF. Expanded Program on Immunization (EPI): A Bangladeshi Success Story; 2012

37. Ahmad SM, Hossain MB, Monirujjaman M, et al. Maternal zinc supplementation improves hepatitis B antibody responses in infants but decreases plasma zinc level. Eur J Nutr. 2015;55(5):1823-1829.

38. Rahsid H RS. Hepatitis B Vaccination in Bangladesh: a Suggestion Based on Current Evidence. Hepatitis Monthly. 2006;6(1):41-44.

39. Karim MF, Al Mahtab M, Rahman S, et al. Non-alcoholic Fatty Liver Disease (NAFLD)-A Review. Mymensingh Med J. 24(4):873-880.;

40. Hossain IA, Rahman Shah MM, Rahman MK, et al. Gamma glutamyl transferase is an independent determinant for the association of insulin resistance with nonalcoholic fatty liver disease in Bangladeshi adults: Association of GGT and HOMA-IR with NAFLD. Diabetes Metab Syndr. 10(Suppl 1):S25-S29.

41. Alam S, Noor E, Alam SM, et al. Nonalcoholic steatohepatitis in nonalcoholic fatty liver disease ;patients of Bangladesh. World $J$ Hepatol. 2013;5(5):281-287.

42. Hossain IA, Akter S, Bhuiyan FR, et al. Subclinical inflammation in relation to insulin resistance in prediabetic subjects with nonalcoholic fatty liver disease. BMC research notes. 2016;9(1):266.

43. Alam S, Mustafa G, Alam M, et al. Insulin resistance in development and progression of nonalcoholic fatty liver disease. World J Gastrointest Pathophysiol. 2016;7(2):211-217.

44. Hossain IA, Akter S, Rahman MK, et al. Gender Specific Association of Serum Leptin and Insulinemic Indices with Nonalcoholic Fatty Liver Disease in Prediabetic Subjects. PLoS one. 2015;10(11):e0142165.

45. Alam S, Gupta UD, Alam M, et al. Clinical, anthropometric, biochemical and histological characteristics of nonobese nonalcoholic fatty liver disease patients of Bangladesh. Indian J Gastroenterol. 2014;33(5):452457.

46. Alam S, Kabir J, Mustafa G, et al. Effect of telmisartan on histological activity and fibrosis of non-alcoholic steatohepatitis: A 1-year randomized control trial. Saudi J Gastroenterol. 2016;22(1):69-76.

47. Fattovich G. Natural history of hepatitis B. J Hepatol. 2003;39(Suppl 1):50-58.

48. Fattovich G, Bortolotti F, Donato F. Natural history of chronic hepatitis B: special emphasis on disease progression and prognostic factors. $J$ Hepatol. 2008;48(2):335-352.

49. Chu CM, Liaw YF. Natural History of Hepatitis B Virus Infection. Hepatitis B Virus in Human Diseases. 2016:217-247.

50. Masarone M, Federico A, Abenavoli L, et al. Non alcoholic fatty liver: epidemiology and natural history. Rev Recent Clin Trials. 2014;9(3):126-133.

51. Adams LA, Lymp JF, Sauver JS, et al. The natural history of nonalcoholic fatty liver disease: a population-based cohort study. Gastroenterology. 2005;129(1):113-121.

52. White DL, Kanwal F, El Serag HB. Association between nonalcoholic fatty liver disease and risk for hepatocellular cancer, based on systematic review. Clin Gastroenterol Hepatol. 2012;10(12):1342-1359.

53. Fazel Y, Koenig AB, Sayiner M, et al. Epidemiology and natural history of non-alcoholic fatty liver disease. Metabolism. 2016;65(8):1017-1025.

54. Sarin SK, Kumar M, Lau GK, et al. Asian-Pacific clinical practice guidelines on the management of hepatitis B: a 2015 update. Hepatol Int. 2016;10(1):1-98. 